Revista Española de

In $\mathrm{v}$ e s t ig a c í́ n

Criminológi ca

\title{
Adentrándonos en la mente de un asesino serial: Entrevistas con Mabou
}

\section{Deep dive into a serial killer's mind: Interviews with Mabou}

Recibido el 20 de mayo de 2015/Publicado el 10 diciembre de 2015

\author{
José Martín Amenabar ${ }^{1}$ \\ Universidad del País Vasco
}

\begin{abstract}
RESUMEN
Este artículo constituye una aproximación psicológica a un asesino serial que mató y enterró en una casa familiar en construcción a dos mujeres jóvenes, a una de las cuales previamente violó, habiendo sido capturado como consecuencia de que su tercera víctima escapara cuando la tenía retenida para violarla y matarla. A lo largo de numerosas entrevistas en profundidad con él se exploraron las circunstancias e interacciones propiciadoras de su conformación psíquica. Se trata de un victimario emocionalmente perturbado, ofuscado en su aislamiento social por su ira y sus fantasías criminales, y sumamente decepcionado con su vida (relacional y sexual), que esperaba sentir mediante las acciones violentas lo que nunca antes había llegado a sentir. Iba en pos de una "obra criminal maestra" por la cual sentirse totalmente satisfecho, "realizado", sin preocuparse por el sufrimiento ocasionado, viéndose y deseoso de ser visto como un justiciero dedicado a eliminar lacras del mundo.
\end{abstract}

\footnotetext{
${ }^{1}$ La correspondencia debe enviarse a: José Martín Amenabar Beitia, Departamento de Personalidad, Evaluación y Tratamiento Psicológico. Facultad de Psicología. Universidad del País Vasco. Avenida de Tolosa, 70, 20018 San Sebastián. Spain. josemartin.amenabar@ehu.eus
} 
Palabras clave: asesino serial, fantasías criminales, psicopatía, entrevistas, aislamiento social, ira, necesidad de sentir, narcisismo patológico.

\begin{abstract}
This article is a psychological approach to a serial murderer who killed and buried two young women in a family house under construction. One of these women had been previously raped. He was captured once his third victim escaped when she was been held to be raped and killed. Along numerous interviews with him the circumstances and interactions that propitiated his psychological profile were explored. $\mathrm{He}$ is an emotionally disturbed perpetrator, obfuscated in his social isolation because of his anger and his criminal fantasies, and extremely disappointed with his life (social and sexual life), who expected to feel through the crimes what he had never achieved before. He searched for a "criminal masterpiece" which would make him feel totally satisfied, "fulfilled", without having to be worried about the suffering caused, feeling himself and eager to be considered as an avenger dedicated to eliminate evils in the world.
\end{abstract}

Key words: serial murderer, criminal fantasies, psychopathy, interviews, social isolation, anger, need to feel, pathological narcissism.

Yo, como el archidemonio, llevaba un infierno en mis entrañas; $\mathrm{y}$, no encontrando a nadie que me comprendiera, quería arrancar los árboles, sembrar el caos y la destrucción a mi alrededor, y sentarme después a disfrutar de los destrozos.

MARY SHELLEY, Frankenstein.

\title{
1. Introducción
}

Un día de mayo de 1998 una muchacha de 17 años logró escapar de una casa en construcción, situada en cierta colonia al norte del Distrito Federal, México, donde había sido llevada a la fuerza por un hombre. Una vez que las autoridades mexicanas tuvieron conocimiento de lo sucedido, se planteó el operativo policial correspondiente y se efectuaron varias averiguaciones en la vivienda, incluyendo diversas excavaciones, a partir de las cuales se puso al descubierto que este victimario, nacido en 1967, al que denominaré Mabou, anteriormente secuestró, mató y enterró a dos mujeres jóvenes (de 25 y 19 años), a una de las cuales previamente violó. Contra su primera víctima actuó a mediados de 1997 y contra la segunda a principios de 1998. Mabou dice haber matado a 
las dos muchachas porque «sentí la necesidad de hacerlo». No las conocía. «Fue al azar». «Me gusta lo que es fuera de lo común y lo hice».

Hay sujetos, como Mabou, que en determinada época de sus vidas empiezan a fantasear con la idea de cometer un asesinato y que finalmente llegan a matar a alguien (que generalmente no conocen) por "necesidad" psicológica. Pasado cierto tiempo, sienten nuevamente la necesidad de matar, fantasean con la idea de volver a hacerlo y lo hacen. Son los asesinos seriales, una variedad de depredadores de seres humanos que van cometiendo sus homicidios en diversas secuencias temporales. En la definición comúnmente aceptada al respecto, tal como observan Garrido y López Lucio (2006), se describe a un individuo que mata a tres o más personas en diferentes momentos que van intercalados con períodos de «enfriamiento» durante los cuales el asesino en cuestión no siente (o si siente, es capaz de controlar) la urgencia de matar. No obstante, el criterio numérico de tres o más víctimas es objetable, «porque en ocasiones el responsable de una o dos muertes no comete un tercer asesinato debido a que resulta capturado con anterioridad» (Garrido \& López Lucio, 2006, p. 22), no por falta de ganas. Y en la medida que su inclinación era la de seguir matando si nadie ni nada se lo hubiera impedido, hay investigadores que contemplan como criterio numérico suficiente la comisión de dos asesinatos.

Entre los asesinos seriales algunos de ellos, diagnosticados como psicóticos, pueden haber cometido los crímenes por sus problemas de reconocimiento de la realidad, inconscientes del daño causado, mientras que otros se han adentrado en una vorágine de muertes periódicas a sabiendas de lo que hacían y sin sentirse, por lo menos aparentemente, conmovidos por el sufrimiento ocasionado; a estos últimos, debido a la insensibilidad afectiva mostrada junto con otras características de personalidad, cabe diagnosticar como psicópatas. Y tal como informa Skrapec (2000), los estudios efectuados sobre los asesinos seriales señalan la psicopatía como patología predominante. De todos modos, teniendo en cuenta que muchos psicópatas $^{2}$ no son delincuentes (así como muchos delincuentes no son psicópatas) y que la mayoría de los delincuentes psicópatas no son asesinos seriales, hemos de considerar que «la psicopatía por sí sola no explica las motivaciones de un asesino serial» (Morton \& Hilts, 2008, p. 14).

\footnotetext{
${ }^{2}$ Para ahondar en el tema de la psicopatía pueden consultarse los trabajos de Hare (1984, 2000, 2003).
} 
El diagnóstico psicopatológico no resulta suficiente «para explicar por qué alguien siente la necesidad de matar una y otra vez. Necesitamos conocer mejor al asesino en serie como individuo: tenemos que examinar el mundo tal como él lo experimenta» (Skrapec, 2000, p. 163). Más allá de clasificarlo psicopatológicamente, el propósito radica en conocer cuáles son los acontecimientos fundamentales de su vida, cómo le han afectado o los ha vivido y qué significados otorga a sus actos, sin perder de vista en este proceso de investigación el tipo de relación o interlocución establecido con el investigador. Obviamente se trata de una metodología cualitativa y, como tal, «es naturalista, participativa e interpretativa» (Kerlinger \& Lee, 2002, p. 533), fundamentada en el análisis del discurso y caracterizada por su flexibilidad o poca estructuración, lo que se visualiza durante las entrevistas.

Cuando se aborda un estudio de caso desde la perspectiva de la subjetividad, más que plantear una hipótesis por la cual anticipar algo, el proceso de investigación se articula como apertura al discurso (significativo) del otro, para poder enfocar la atención y el nivel de análisis en las temáticas o problemáticas que le afectan (y a veces obsesionan), tratando de hallar en la madeja de su discurso (resultado de operaciones defensivas ante sucesos traumáticos, conflictos y/o carencias) las claves descifradoras o explicadoras de su conformación psíquica. Para ello, con objeto de estructurar la propuesta de análisis del caso Mabou, me he basado en las aportaciones realizadas por relevantes autores así como en el conocimiento que yo mismo he ido adquiriendo al entrevistar y analizar a numerosos reclusos.

Como tesis general de investigación me baso en la idea de que el sujeto violento lo es porque, no habiendo tenido capacidad o posibilidad de procesar sus heridas emocionales, sintiéndose mal consigo mismo, necesita tomar al otro como objeto depositario de su malestar o sufrimiento ${ }^{3}$ (Bion, 1996; Miller, 1998; Winnicott, 1993). Tengamos en cuenta que en el pasado infantil de los victimarios (o más concretamente en el de los asesinos seriales ${ }^{4}$ ) podemos encontrar episodios de maltrato y/o una perniciosa soledad (Bowlby, 1982; Dutton \& Golant, 1997; Fromm, 1967; Garrido,

\footnotetext{
${ }^{3}$ Para conocer mis reflexiones y consideraciones acerca de los fenómenos violentos puede consultarse: Amenabar (2014).

${ }^{4}$ Tal como apunta Meloy (2000), Ressler y sus colaboradores fueron los primeros investigadores en estudiar detenidamente los antecedentes de los homicidas sexuales, habiendo descubierto que muchos de ellos provenían de familias con alcoholismo, enfermedades psiquiátricas y criminalidad y que en un porcentaje significativo padecieron maltrato físico y abuso sexual.
} 
2007; Martens, 2001; Meloy ${ }^{5}$, 2002; Miller, 1998; Miller, 2014; Palermo, 2008; Reich, 1980; Ressler, Burgess \& Douglas, 1995; Ressler \& Shachtman, 1995; Rojas Marcos, 2004; Winnicott, 1996). Experiencias patógenas. Alimentadoras de resentimiento y deseos de venganza contra el mundo.

En el libro Sexual homicide: Patterns and motives, Ressler, Burgess \& Douglas (1995) informan de ciertas situaciones y conductas que los asesinos habrían vivido o protagonizado con frecuencia durante la infancia: fantasías (82\%), masturbación compulsiva $(82 \%)$, aislamiento $(71 \%)$, mendacidad $(71 \%)$, enuresis $(68 \%)$, rebeldía (67\%), pesadillas (67\%), destrozos de la propiedad (58\%), incendios (56\%), robos (56\%), crueldad con los niños (54\%), pobre imagen corporal (52\%). Estos índices son relativamente estables en el tiempo. Por ejemplo, en lo que respecta a la incidencia del aislamiento social entre los asesinos, el porcentaje de su aparición en la niñez era un $71 \%$, en la adolescencia un $77 \%$ y en la etapa adulta un $73 \%$.

Los asesinos seriales (Garrido, 2007; Martens, 2001; Palermo, 2008; Ressler \& Shachtman, 1995) suelen ser solitarios. «La mayor parte de ellos han crecido tímidos, solitarios, extremadamente sensibles, con sentimientos de ser rechazados, no amados y abandonados y albergando una hostilidad básica hacia personas específicas y/o a todo el mundo [...]. La mayoría manifestaría algunos o todos los criterios para conductas desordenadas en la infancia y desórdenes de la personalidad antisocial, narcisista y/o esquizoide en la adultez» (Miller, 2014, p. 13).

\section{Método}

El presente artículo constituye un estudio sobre Mabou a partir de determinados extractos correspondientes a las 25 entrevistas $^{6}$ en profundidad que le realicé a lo largo de sucesivas visitas a la cárcel entre junio de 1999 y noviembre de 2000.

\subsection{Participante}

\footnotetext{
${ }^{5}$ Para conocer algunas de las tesis psicoanalíticas preponderantes sobre la violencia destructiva pueden consultarse los trabajos de Meloy (2002) y de Yakeley \& Meloy (2012).

${ }^{6} \mathrm{He}$ de decir que he realizado algunas pequeñas modificaciones gramaticales en el relato de Mabou, que en absoluto alteran su contenido, con objeto de favorecer su lectura y seguimiento.
} 
Nombre ficticio: Mabou

Sexo: masculino.

Año de nacimiento: 1967.

Composición familiar: madre, padre y ocho hermanos (cinco varones y tres mujeres).

Ocupación de la madre: ama de casa.

Ocupación del padre: vendedor de bienes raíces.

Orden de nacimiento de Mabou: el menor de los hermanos.

Estado civil: soltero.

Hijos: no tiene.

Nivel de estudios: educación secundaria sin finalizar.

Ocupación: carpintería.

Edad de inicio de las fantasías homicidas: entre los 17 y 18 años.

Edad de inicio de las relaciones sexuales: 28 años.

Edad al inicio de la andadura homicida: 30 años.

Períodos de los crímenes: mediados de 1997, principios de 1998, mayo de 1998.

Fecha de inicio del proceso de entrevistas: junio de 1999.

Edad al inicio del proceso de entrevistas: 32 años.

Fecha de finalización del proceso de entrevistas: noviembre de 2000.

Situación penal: al término del proceso de entrevistas, en noviembre de 2000, Mabou llevaba algo más de dos años encarcelado. Tenía una condena de 50 años.

\subsection{Duración del proceso de las entrevistas}

Aproximadamente un año y medio. Las entrevistas con Mabou se interrumpieron repentinamente debido a su traslado a un centro psiquiátrico penitenciario, lo que nos impidió explorar y ahondar en ciertos pasajes infantiles y del desarrollo psicosexual. Realmente yo hubiera deseado continuar con el proceso de entrevistas hasta el momento de acordar entre los dos el punto final. En mi mente estaba la idea de volver a verle, 
hablar de su situación tras el tiempo transcurrido, agradecerle su participación en la investigación y cerrar el tema de nuestra separación. Este encuentro pudo darse años después (un día de agosto de 2005), una vez que se encontraba nuevamente en la cárcel donde yo lo visitaba.

\subsection{Lugar y contexto de las entrevistas}

El lugar de las entrevistas fue casi siempre en un patio exterior; las restantes veces en su celda. Sin ningún tipo de vigilancia o control, sin ninguna presencia adicional. Los dos a solas. Iniciábamos las entrevistas entre las 10.00-11.00 horas, en función del tiempo que precisaba yo para llegar desde Cuernavaca hasta el Distrito Federal y desde ahí viajar a la prisión, más el tiempo correspondiente para pasar por los controles pertinentes hasta llegar al espacio de encuentro concertado con Mabou. Antes de salir de la prisión era habitual que me entrevistara con el director para comentar algunas cuestiones criminológico-penitenciarias, además de agradecerle sus atenciones para conmigo.

\subsection{Duración de las entrevistas}

Entre dos y tres horas, dependiendo de cómo nos encontráramos, del tiempo y de la temperatura que podía hacer, y de la posibilidad de que recibiera una visita familiar. Las entrevistas pasaban bastante rápido, tanto para él como para mí.

\subsection{Premisas de la investigación}

Las entrevistas con Mabou, así como las que he mantenido con otros reclusos en distintas cárceles mexicanas, se han llevado a cabo con arreglo a las siguientes premisas: 1) Total voluntariedad y libertad del recluso para participar, sin que la aceptación o rechazo suponga consecuencias penitenciarias, y con la garantía de tener plena libertad para poder contestar o callar según lo crea conveniente o desee, además de tener la posibilidad de interrumpir temporal o definitivamente el proceso de entrevistas. 2) Uso científico de la información, comentándosele al recluso desde un principio que el objetivo de la investigación es conocer las condiciones de vida por las 
cuales ha llegado a ser y comportarse de determinada manera y poder contribuir con el conocimiento psicológico adquirido a la prevención de la criminalidad. En las entrevistas carcelarias suelo presentarme en mi condición de profesor e investigador, como alguien diferente y diferenciado del personal del ámbito penitenciario, lo que ayuda a establecer la necesaria relación de confianza con el recluso en cuestión así como a evitar o disminuir sus recelos sobre el uso de la información aportada.

\subsection{Tipo de entrevistas}

Las entrevistas eran semiestructuradas. Yo disponía de un guión de preguntas que me servían de base en la recogida de datos, con objeto de cumplimentar ciertas áreas temáticas y sus elementos nucleares, aunque siempre con la idea y la convicción de que las preguntas eran un pretexto o camino inicial en la conversación con Mabou, que todo pasaba por establecer y mantener una relación (de confianza y de acogimiento) en la exploración de su ser. De hecho, él me agradecía mucho que le brindara un espacio de diálogo, intercambio y conocimiento de sí mismo.

Durante las entrevistas abordamos todo tipo de temas (historia familiar, infancia, adolescencia, etapa adulta, carrera delictiva, situación penitenciaria, sexualidad, opiniones sobre la sociedad y la religión, etc.), con la progresiva profundización que facilita la suma de horas y sesiones de encuentro interpersonal, lo que me dio la oportunidad de conocer hondamente el mundo perceptivo-relacional-fantasmático de Mabou. Algunas preguntas que yo le formulaba eran abiertas mientras que otras estaban orientadas a detallar o precisar ciertas declaraciones, pero en todo caso siempre con total libertad para que pudiera transitar de un tema a otro o seguir hablando por asociación de ideas o para poder sumergirse en sus silencios. En distintas ocasiones y sesiones volvíamos a temas ya tratados, bien porque él necesitaba hacerlo o bien porque yo quería seguir adentrándome todavía más en el conocimiento de su persona, planteándole para ello un nuevo retorno a ciertas circunstancias y experiencias de su vida.

\subsection{Recogida de información}


Las entrevistas que realizaba eran registradas con una grabadora de sonido, para lo cual contaba con la pertinente autorización penitenciaria y el consentimiento del propio Mabou. Aunque eventualmente yo tomaba algunas notas en un cuaderno, que me servían en un tiempo posterior para revisar y reflexionar sobre los temas tratados en las diferentes sesiones, prefería disponer de la tranquilidad de no tener que estar pendiente de una recogida minuciosa y continuada de la información para poder centrarme así en el encuentro y la relación con Mabou.

\subsection{Análisis de la información}

Con toda la información recabada a lo largo de las 25 entrevistas en profundidad (con ciertos asuntos tratados y retomados en sesiones que podían estar separadas por bastantes o muchos meses entre sí, a pesar de lo cual emergía una estabilidad o coherencia discursiva que se reflejaba en la presentación de aspectos coincidentes o complementarios, en un cuerpo de información que se iba detallando progresivamente en una misma línea declaratoria), procedí a leerla toda y luego a desglosarla en diferentes apartados, para posteriormente proceder a entresacar los elementos más significativos del discurso de Mabou. Y digo “entresacar" porque fundamentalmente lo que he llevado a cabo ha sido una labor de análisis fenomenológico, esto es, una labor por la cual poner de relieve, con palabras del propio Mabou, los hechos delictivos protagonizados y los sucesos de vida más relevantes desde su infancia hasta la época de las entrevistas. Y además me he permitido aportar un análisis de tipo psicodinámico, con objeto de dar explicación al proceso de su conformación psíquica.

\section{Resultados}

A la hora de ir desgranando y analizando las áreas temáticas fundamentales del discurso de Mabou, encontré que: 1) El prematuro y continuado aislamiento social tuvo efectos dañinos sobre su desarrollo psicológico, lo que le hizo refugiarse en fantasías destructivas; 2) La necesidad de estimulación destructiva remitía a su dificultad para sentir afecto y/o placer (Reich, 1985, 2006), lo cual se corresponde con lo acontecido a 
los victimarios que ejercen la violencia para subsanar su incapacidad de sentir (Fromm, 1997; Skrapec, 2000).

Con el propósito de acercar al lector al mundo imaginario-experiencial de Mabou, en las páginas siguientes voy a articular mi exposición y análisis en torno a 7 epígrafes.

\subsection{Perfil psicológico del victimario}

En un informe pericial psicológico, realizado en mayo de 1998, se dice lo siguiente acerca de Mabou: 1) Presenta inmadurez emocional con carácter cambiante, un concepto de sí mismo pobremente integrado y pasa de actitudes de autodevaluación e inseguridad a sentimientos de omnipotencia como un mecanismo de compensación, buscando la afirmación de su virilidad a través de su conducta ilícita. 2) Es una persona activa, impulsiva, con alto nivel de energía, con baja tolerancia a la frustración que lo apremia a satisfacer sus necesidades y lograr éxitos en todas las actividades que le ofrezcan intensidad vital y experiencia plena. 3) Percibe a la mujer como una figura amenazante.

En varios estudios se ha destacado que Mabou sabía lo que estaba haciendo en el momento de los crímenes, que él actuó con capacidad cognoscitiva y pleno reconocimiento de la realidad. Y puesto que presentó y seguía presentando actitudes de menosprecio hacia el sufrimiento de las víctimas y sus familiares, sin mostrar indicio alguno de sentimiento de culpa, fue diagnosticado por algunos médicos como psicópata. El mismo Mabou reconoce en numerosas entrevistas conmigo que le resultaba sorprendente no haber sentido nada por el hecho de matar, ni siquiera el azote de su conciencia. Insensibilidad emocional. Anestesia moral.

Algunas peculiaridades que Mabou despliega habitualmente en sus interacciones son la susceptibilidad, la desconfianza, la actitud persecutoria, y la excepcionalidad de la empatía y del sentimiento de culpa. De todos modos, en lo que respecta a nuestra relación, a lo largo de los sucesivos encuentros que mantuvimos, Mabou se mostró accesible y colaborador conmigo, confiado en que no iba a hacer un mal uso de la información que me iba facilitando, tal vez porque me veía como alguien honesto y guiado por el conocimiento científico. Las referencias que me aportaba en sucesivas 
fechas, algunas de ellas muy lejanas entre sí, mantenían una misma línea declaratoria, y no eran precisamente expresión de una imagen inocente o exculpatoria de sí mismo, pues reconocía su participación en los hechos delictivos.

Cabe destacar que no es completamente insólito que un victimario se muestre sincero en ciertos encuentros o con respecto a ciertas personas, aun cuando en otras ocasiones o entrevistas o con otros interlocutores pueda utilizar el "arte" del engaño y la manipulación. Todo ello depende en gran medida del examen que este sujeto haga en determinada situación, si cree que ha de guiarse por el instinto de supervivencia o si opta por exponer y compartir su visión peculiar de la existencia.

Durante nuestros encuentros, Mabou presentaba un porte un tanto apagado y encogido, poco enérgico, poco atrevido en sus interacciones, tímido, con tendencia al retraimiento social, como si hubiera que presionarlo y animarlo constantemente a interaccionar. De hecho, la mayoría de sus respuestas eran breves, por lo que, para poder mantener y profundizar en el hilo de su relato, me veía en la necesidad de realizarle un gran número de preguntas, así una y otra vez, en las sucesivas entrevistas.

Mabou se mostraba parco en palabras y con un discurso bastante monótono, plano, independientemente del tema abordado en un momento dado. En las ocasiones que hablamos de los crímenes cometidos no daba muestras de sentirse alterado o nervioso ni tampoco emocionado. Sus palabras discurrían sin apenas cambios de ritmo, ni interjecciones, sin énfasis, impasiblemente, según él, «como si estuviéramos hablando de otra cosa, lo normal».

\subsection{Modus operandi}

A la primera víctima «la amenacé con un arma», concretamente con una pistola. «Lo que más me sorprendió es que se portó muy dócilmente. Le indiqué que no se moviera, que no gritara, que se metiera en la casa; entonces la metí y allá adentro la amarré y la amordacé». «Mientras ella estaba amordazada y atada, yo me dormí un rato y en ese rato tuve una convulsión, o sea, tuve un ataque. Entonces desperté un poco tenso y nervioso. Fue cuando decidí matarla porque ya no sabía qué hacer con ella. Si la dejaba ir, me iba a denunciar. Primero escarbé un hoyo en el piso y después la maté y la metí, la enterré». Mabou la mató propinándole un golpe en la cabeza con un palo. El 
secuestro lo habría cometido como a las diez de la noche y el homicidio, casi amaneciendo, como a las seis de la mañana. Durante ese lapso, él habría estado dormido aproximadamente tres horas. A esta mujer no la violó porque «no lo pensé en ese momento».

A la segunda víctima Mabou la abordó con la misma arma, como a las once de la noche. Lejos de oponer resistencia, parecía pensar que aquello no iba en serio. «Cuando la estaba amarrando recuerdo que ella hacía bromas». La ató, la amordazó y esperó un rato, aproximadamente una hora. «Como a las doce de la noche fue cuando la subí al piso de arriba y en un cuarto pequeño puse una colchoneta sobre el piso y fue ahí cuando me vino la idea de violarla». Desatándole los pies y manteniéndole las manos atadas, amordazada y con una venda en los ojos, Mabou la tumbó en la colchoneta (pues en la casa familiar en construcción no había ninguna cama), la desvistió y la violó. Luego la volvió a vestir y a atar los pies, y la tapó con una cobija, arrinconándola en la colchoneta. «Me acosté al lado de ella y ella se quedó profundamente dormida». «Dormité. Como a eso de las ocho de la mañana me levanté. Empecé a cavar el agujero y una vez que lo terminé de cavar fui a por ella, la bajé, hice que se metiera en el agujero en cuclillas, le coloqué la pistola en la cabeza y le di un disparo». Desde que secuestró a esta muchacha Mabou tenía la idea de matarla. Si bien en la primera ocasión el asesinato fue algo que se le habría ocurrido en el momento, en el segundo caso, con su segunda víctima, ya tenía pensado de antemano acabar con su vida. A la primera de las víctimas Mabou la mató golpeándola con un palo, y no de un disparo, para evitar que los vecinos de la casa colindante escucharan la detonación. A la segunda víctima la mató de un disparo, porque ya no vivía nadie en la vivienda contigua, además de que se le hizo una manera muy rápida de terminar todo.

A la tercera víctima Mabou la abordó y secuestró igual que a las dos anteriores. «La amordacé. A ella también tenía pensado violarla. La subí al piso de arriba y ahí la introduje en un cuarto; entonces la amarré, pero no la amarré bien. Bajé, no recuerdo por qué, al piso de abajo y ella se pudo desatar y se escapó por la ventana». «Ya ni modo. Esperé a ver qué sucedía». Mabou refiere que la secuestró aproximadamente a las once de la noche y que ella logró fugarse como a la una de la mañana. Luego durmió. Despertó como a las cinco de la mañana, salió de la casa y viajó en autobús a otra ciudad. Aunque Mabou pensó que como consecuencia de la fuga de la víctima 
finalmente las autoridades lo arrestarían, acusándole de secuestro y con alta probabilidad de descubrir todo lo demás, «no me preocupaba mucho. Por eso pude dormir». A Mabou lo aprehendieron en casa de uno de sus hermanos, fue juzgado y encarcelado.

\subsection{Períodos de "enfriamiento"}

Después de haber matado y enterrado a la primera víctima, como a las ocho de la mañana, Mabou salió de la casa y tomó un autobús en dirección a otra ciudad. Durante el viaje tuvo los siguientes pensamientos: «Acabo de matar a una persona. Antes me preguntaba qué se sentiría al matar a una persona, pero no se siente nada». "Yo esperaba sentir algo». Esto contrasta con otras palabras del propio Mabou, cuando dice: «Al haber hecho eso, secuestrarla y tenerla ahí, sentía cierto placer, como que había logrado algo». «Me sentía diferente, me sentía bien por haberlo hecho». Podemos considerar entonces que Mabou se sentía satisfecho por haber traspasado los umbrales de la cotidianidad, por haber concretado una ideación criminal por la cual sentirse especial, pero al mismo tiempo estaba bastante decepcionado de que ello no le hubiera supuesto un incremento en su capacidad de sentir.

Entre el primer homicidio y el segundo transcurrió aproximadamente medio año. Durante los primeros meses de ese período Mabou se sentía frustrado por no haber sentido nada al matar a una persona. Y apenas fantaseaba. Luego fue variando la ideación criminal, con la incorporación de aspectos novedosos. «Antes del primer crimen fantaseaba con cometer un crimen simple, digamos que dispararle a una persona, golpearle con un garrote, atacarle con un puñal. Pero después del primer crimen empezaron a ser fantasías más fuertes, digamos que ahogando a las personas, quemándolas, haciéndoles sentir más sufrimiento». «Yo creo que, por eso, el segundo crimen me llevó a la violación, intentando causar más daño para ver si así sentía yo algo».

Durante el período en que empezó a considerar la idea de volver a matar, variando o modificando su ideación criminal, sus fantasías se hicieron recurrentes. «Fantaseaba casi todos los días». «Veía a una persona y me venía a la mente cómo le 
haría esto o aquello». «Las fantasías iban en aumento». Y el hecho de que las fantasías homicidas fueran dándose con mayor frecuencia, hacía incrementar en Mabou su inquietud por volver a matar. Así estuvo aproximadamente un mes, en un estado de excitación in crescendo, fantaseando más y más. «Supe esperar a que se diera el momento adecuado. Anteriormente fui a la casa en varias ocasiones, pero no pude hacerlo con nadie, no hubo ninguna muchacha que pasara». Hasta que llegó el día en que por la noche, cerca de la vivienda, vio aparecer a la que convertiría en su segunda víctima. «Durante la violación me sentía excitado, pero cuando terminé no sentí nada, no sentí satisfacción». «Esperaba sentir un orgasmo fantástico, sensacional, pero no sentí nada». "Yo me preguntaba qué tan fantástico se puede sentir un orgasmo. Me imaginé sentir un orgasmo así. Por eso me vino a la cabeza la violación».

Con el segundo homicidio «me sentí igual que mi primera vez». «No sentí nada, me sentía decepcionado», aunque también sentía cierta satisfacción por haberlo hecho. Refiere Mabou que aproximadamente durante un mes sus fantasías homicidas disminuyeron un poco y que posteriormente retornó su inquietud y su necesidad de matar. El tiempo transcurrido hasta que volvió a actuar contra su tercera víctima fue de aproximadamente cuatro meses. Mientras tanto recordaba los crímenes cometidos.

En cada uno de los períodos intercalados entre sus acciones criminales (que en el primero es de unos 6 meses y en el segundo es de unos 4) se da inicialmente en Mabou una fase de decepción y decaimiento para luego reactivarse en él su producción fantasiosa, su excitación y su fascinación por el exterminio. Su deseo destructivo. Con el pensamiento orientado a mejorar la realización de un homicidio que pueda conllevar una mayor satisfacción. Hemos de tener en cuenta que «El acto de matar deja al asesino descontento y en tensión, porque no es tan perfecto como su fantasía» (Ressler \& Shachtman, 1995, p. 47). Precisamente para referirse al estado de desasosiego posterior al crimen que caracteriza a este tipo de victimarios, Robert Ressler, agente del FBI, acuñó el término "asesino serial” por asociación con lo acontecido al espectador de las series televisas, cuando al final de cada episodio se genera gran suspense, una espera expectante por ver el siguiente capítulo. No se trata de un final cerrado ni muy grato, puesto que aumenta la tensión. Un peculiar estado psicológico que engancha y empuja a la reiteración. 
A este respecto, tenemos los comentarios de Mabou acerca del gozo perseguido a través de los crímenes: «A veces todavía siento una satisfacción por haberlo hecho». «Me siento satisfecho, aunque a veces no, como que faltó algo». «Por eso cometí varios crímenes, porque me sentía insatisfecho». «Cuando se espera algo con ansiedad y no se siente nada, se queda uno defraudado, esperando que vuelva a suceder para ver si en la próxima ocasión se siente algo». No puede saberse a cuántas mujeres hubiera llegado a matar en el caso de no haber sido detenido. «Yo no tenía ningún número determinado. Tal vez ya no me daban ganas de hacerlo o lo volvía a hacer». «Deseaba cometer un crimen que me dejara bien satisfecho; tal vez sería el último que hiciera». Fantaseaba cometer varios homicidios «hasta lograr mi obra maestra».

\subsection{Una infancia enfermante}

\section{a. Ataques y aislamiento social}

«Desde chico yo tuve un problema, me daban ataques». «Nunca supe qué tipo de ataques eran. Aún me siguen dando. Unos médicos decían que eran ataques epilépticos y otros decían que no». «Cuando empieza un ataque se me adormece la lengua, la mandíbula con la lengua, y me viene la convulsión, pero no pierdo el sentido». La primera vez que le ocurrió algo así Mabou tenía unos cuatro años y tanto sus padres como sus hermanos se asustaron mucho. Y ese fue el comienzo de una sucesión de ataques que han ido variando en su frecuencia. «A veces era a diario, a veces cada tercer día». «Actualmente hay veces que pasa un mes sin darme un ataque y hay veces que en un día me dan dos; son ataques muy irregulares». «Los ataques me vienen cuando estoy dormido». «Cuando me va a empezar a dar el ataque me despierta».

Las frecuentes consultas médicas le hicieron perder a Mabou muchas clases, lo que afectó a su rendimiento escolar. Los compañeros de escuela «como estaban enterados de que me daban ataques, me rechazaban». «Los niños a veces se burlaban de mí, por la enfermedad que yo tenía. Me daba coraje y a veces imaginaba cómo castigarlos, aunque nunca lo hice». «Me acostumbré a andar solo». No tenía ningún amigo. No tenía con quien jugar ni con quien cometer travesuras. Con los hermanos 
tampoco jugaba debido a la gran diferencia de edad con ellos; el hermano más próximo en edad es seis años mayor.

«Yo me encerré en mi propio mundo. La casa era mi mundo. El exterior no me llamaba la atención». «No disfruté de la compañía de amigos o compañeros y no la deseaba al mismo tiempo». «Disfrutaba de la soledad». «Jugaba con mis primos cuando íbamos a visitarlos o ellos venían de visita, pero era un momento de juego corto; nada más estaban por un rato, con eso me bastaba, me desahogaba». «Se desahogaba toda esa inquietud que tenía yo por saber qué se siente al jugar con otras personas o qué se siente al estar con otros compañeros». «Llegaba un momento que me sentía muy saturado de esa compañía y necesitaba estar solo».

Ni durante la infancia ni tampoco durante la adolescencia tuvo Mabou amigos. El conocimiento de la amistad le llegó en la edad adulta, como a los 28-29 años. «Han sido pocos amigos». «Lo que me gusta de una persona es que pueda platicar de religión, ciencia, filosofía, de muchas cosas». «A mí me gustaba la forma en que ellos platicaban. Como hablaban de varios temas, me llamaba la atención, pero fuera de eso me seguía sintiendo mejor estando solo». «No sé si era una relación profunda de amistad, porque de todas formas no confío en nadie». «Siento que me van a traicionar».

\section{b. Susceptibilidad y vulnerabilidad oculta}

Durante la secundaria, en varias ocasiones, Mabou sintió traicionada la confianza depositada en sus compañeros; «les decía yo un secreto y lo comentaban, o tenía yo alguna duda o problema y me informaban de manera errónea para que lo hiciera mal. Por eso aprendí a no confiar en nadie». «Ha habido personas que han intentado hacerme pasar por un torpe, un inútil». «En las únicas personas que confío son las de mi familia». «Yo casi no salía. Pasaba mucho tiempo encerrado, en mi habitación y mi casa. No me gustaba salir. A veces pasaba hasta una semana» en casa sin salir. «Cuando me encuentro solo me siento muy feliz, pudiendo hacer las cosas que yo quiero, que nadie me contradiga».

Mabou destaca como algo muy pernicioso en su infancia «los maltratos de los maestros, de las maestras más que nada». «Faltaba mucho porque mi mamá me llevaba al doctor. Perdía muchas clases; no me sabía las lecciones y me golpeaban». «Mis 
calificaciones en la primaria eran buenas; sacaba ocho o nueve. Cuando iba en segundo de secundaria mis notas eran bajas. Reprobé el curso. Tuve que repetir». Cuando iba en tercero de secundaria Mabou abandonó los estudios. Tenía unos 15 años ${ }^{7}$. Lo hizo porque se le dificultaba aprender. La decisión de abandonar la escuela disgustó a sus familiares; pensaban que «era un flojo». Nadie (ni sus padres ni sus hermanos) sabía de sus problemas escolares. «No me gustaba que se metiera nadie en mis problemas». «Lo guardaba todo. Mis problemas nada más los conocía yo».

«No me gustaba que me criticaran y que me dijeran lo que tenía que hacer». Rehusaba solicitar ayuda o apoyo, con temor a ser criticado (por los padres y hermanos), problemática que se ha diluido a partir de la comisión de los crímenes. «Desde que sucedió esto ya cambió todo. Ya no temo ser criticado». A este respecto, en una de las entrevistas le planteé a Mabou que curiosamente, cuando más razones existían para censurarlo, ya no padeciera el miedo a ser juzgado o criticado. Y entonces me contestó lo siguiente: «Sí, es curioso, pero así es».

\section{c. Sobreprotección parental y obediencia}

En el tiempo que le hago una de las entrevistas, el 15 de julio de 1999, Mabou tiene 32 años. En su familia son ocho hermanos: cinco varones y tres mujeres. Viven los ocho. Su madre también vive y tiene 73 años. Su padre falleció a los 60 años, en 1986. Mabou es el menor de los ocho hermanos. Dice que ellos siempre le han tratado bien y él a ellos.

«Mis padres me protegían mucho, por ser el menor me sobreprotegían, también por lo de mi enfermedad». Su madre no quería que sus compañeros le inculcaran malos hábitos, por ejemplo, el de las drogas. No tenía prohibido salir con ellos, pero como «yo veía que no le gustaba, entonces para no contradecirla, prefería no ir». Temía contrariarla. Ni Mabou ni sus hermanos han retado o desafiado la voluntad de sus padres. Hacían lo que les pedían o lo que ellos consideraban apropiado y aceptable.

\footnotetext{
${ }^{7}$ Tras su etapa escolar Mabou estuvo «sin hacer nada» algo más de tres años, hasta los 18-19 años. Luego trabajó como carpintero aproximadamente cuatro años. Posteriormente estuvo un tiempo «sin hacer nada, pintando, dibujando, haciendo cuadros». Volvió a entrar en varios talleres de carpintería. Entraba y salía. No duraba mucho tiempo. Y dejó de trabajar. «Con lo poco que sacaba de los cuadros y con lo poco que me daban mis familiares me mantenía».
} 
Mabou comenta que la relación entre sus padres era buena, que se llevaban bien. De su madre dice que «es muy alegre». «Mi mamá tiene buen carácter». «Mi padre era más estricto, era más severo. Nunca me golpeó, ni tampoco a mis hermanos, pero su carácter era muy serio». «Llevaba una buena relación con él. Como trabajaba en bienes raíces, tenía su oficina y a veces iba yo a ayudarle a contestar el teléfono o a repartir volantes». «Sentí mucho su muerte». «Se enojó mucho cuando dejé de estudiar». Esa vez, de manera excepcional, Mabou tomó una decisión inaceptable para su padre. Por momentos se sentía molesto con él, por ejemplo, «cuando no me dejaba hacer alguna actividad que yo quería hacer». No obstante, «nunca me enojé con mi papá». «Sí me molesté, pero directamente nunca se lo dije». «Cuando veía que no se podían hacer las cosas, me resignaba».

«Tuve predilección por mi mamá; es la que siempre estuvo a mi lado, la que me llevaba al médico». «Si yo quería ir al cine, tenía que ir acompañado de alguno de mis hermanos. Temía que me fuera a dar un ataque». «En la escuela cuando pedían hacer trabajos de ir al museo yo nunca fui con los compañeros. Me hubiera gustado ir con los compañeros, pero mis padres no me dejaban por miedo a que me fuera a pasar algo y yo les obedecía». Otro ejemplo: «cuando necesitaba comprar algo para la escuela, ellos eran los que me lo compraban». «Como ellos me daban la protección, yo la aprovechaba»; «a veces me molestaba, pero no siento rencor por ello. Al contrario, les agradezco a mis padres que se preocuparan por mí. Nunca me golpearon».

Acerca de la sobreprotección parental «por una parte siento que estuvo mal. Cuando salía a hacer algo o a comprar algo, como siempre me lo hicieron ellos, sentía temor, como que no lo iba a hacer bien». La sobreprotección paterna duró hasta la muerte del padre, cuando tenía casi veinte años, lo que coincidió con el inicio de la disminución de la protección materna. «Entonces me sentía muy temeroso para hacer las cosas».

\subsection{Angustia e ira}

Mabou dice sentirse «mal de los nervios» y que en la cárcel no hay presupuesto para comprar el medicamento que le tranquiliza, el epamin, por lo que le dan diazepam y unas pastillas azules que no sabe qué son. No se siente a gusto con estas medicinas. Sus 
familiares le compran carbamazepina. Está moviéndose nervioso durante todo el día. «En la noche, nada más al dormir, es cuando descanso». «Yo me siento sano de salud mental, nada más que me dan calmantes».

A Mabou le pone muy nervioso el hecho de estar entre mucha gente, entre la multitud. «Siento que va a pasar algo. De antemano sé que no me va a pasar nada, pero siento esa angustia». «Como yo siempre he sido un solitario, al ver mucha gente no sé lo que me pasa, pero siento eso». El concepto de "mucha gente" hace referencia a «más de cinco personas; entonces ya me siento mal». También está «ese interminable coraje que siempre traigo, la angustia cuando hay muchas personas». «Desde adolescente he sentido ese coraje». «Cuando ya no veo gente empiezo a calmarme». «A veces me daba coraje hasta por ver cuando alguien escupía en el suelo. Y me ponía a imaginar la forma de matarlo». «A mí también me da mucho coraje que maltraten a los animales ${ }^{8}$. Cuando veía que golpeaban a un perro me imaginaba cómo hacerle algo a esa persona, cómo torturarle y todo eso, hacer que sufriera».

\section{a. Fantasías homicidas y de exterminio}

«Si me encuentro muy enojado, disfruto mucho con las fantasías criminales». «Por ejemplo, digamos que llegan varios compañeros y se entabla una conversación y hay algunos que me caen mal. En ese momento me entran las ansias de no estar con ellos o empiezo a fantasear cómo eliminarlos». «Si son personas agradables disminuyen las ansias de matar, pero no desaparecen». «Cuando más me vienen estas fantasías es por la noche, a la hora de dormir». «A veces me dan ataques de ira». Durante esos ataques «rompía cosas, lo que veía lo rompía».

«Hay que eliminar a los parásitos. Desde tiempo atrás me gustaba la ideología de los nazis; ellos eliminaban a los que no eran de su raza, se sentían superiores. Aquí no puede haber eso, porque somos mezcla de todo, pero sí podemos eliminar a los parásitos». «Cuando veo a una persona drogándose ${ }^{9}$ a veces pienso que esta gente no debería existir y también pienso cómo eliminarla». «Siempre he tenido en mi mente la idea de eliminar a cierta gente de una forma que sufriera». Para acabar con estos sujetos había pensado «quemarlos, pero lo que más se me grababa y a veces lo soñaba era que

\footnotetext{
${ }^{8}$ A diferencia de los asesinos seriales que han torturado a los animales, Mabou se confiesa un amante de estos seres.

${ }^{9}$ Mabou nunca ha consumido drogas y dice al respecto que no necesita "muletas mentales" para vivir.
} 
los metía en una fosa cerraba y la llenaba de agua. Y se ahogaban». «A veces paso mucho tiempo pensando la manera de matar a la gente». «Sería por medio de asfixia, quemándolos poco a poco, lentamente, quemándolos vivos, o ahogándolos poco a poco, que sientan la angustia. Me gusta que sufra la persona, que sepa que va a morir. Es algo terrible, pero así lo siento».

\section{b. Soñando con una masacre}

«A veces me ha llegado la idea de un exterminio, de un atentado, con una bomba o algo así. Si hubiera tenido la forma de hacerlo, lo hubiera hecho. Hay un sueño que se me repite mucho. En ese sueño veo destrucción, edificios caídos, gente llorando, como si hubiera ocurrido un terremoto o algo así. Voy pasando por la calle y voy viendo la destrucción, y me siento muy feliz, me siento muy contento. Ese sueño se me repite mucho. Veo cadáveres y destrucción, casas caídas, gente llorando, sufriendo. Y yo siento mucha satisfacción. Me siento muy bien, muy alegre. Entre los muertos hay de todo: ancianos, niños, adultos, hombres, mujeres».

«Al cometer un atentado con una bomba hay víctimas inocentes. Sería un asesinato en masa y ahí no se miden las consecuencias sino el grado de destrucción». «No debieron estar donde estuvieron». Con ello conseguiría «admiración de ciertas gentes».

«Yo tenía y tengo un sueño que se me repite mucho. En el sueño me encuentro sobre un gran monte, sobre una pila de cadáveres. Veo hombres y mujeres, pero están muertos. Esa pila de cadáveres es muy grande. Me encuentro hasta arriba de esa pila de cadáveres y siempre me veo vestido de uniforme militar. En la mano sostengo un cuchillo y el cuchillo tiene el filo hacía arriba. Por el filo va caminando un caracol y no se corta». «En el sueño me siento satisfecho de haber hecho algo». Al despertar «siento ansiedad, como cuando alguien siente ganas de hacer algo que dejó pendiente. Me levanto y me pongo a hacer algo para quitarme esa ansiedad».

«En la guerra se puede asesinar sin que lo castiguen a uno. En una ocasión escuché una frase que se me quedó grabada; decían que al que mata a una persona le llaman asesino y que si mata a un millón le llaman conquistador. La cantidad tiene que ver con el castigo por lo hecho». 


\subsection{Ideología persecutoria}

Con respecto a los crímenes cometidos «nunca he sentido culpa ni remordimiento ni nada de eso; simplemente lo recuerdo y ya pasó». «No he tenido ninguna reacción ni arrepentimiento ni nada de eso, ni soñarlo siquiera o tener pesadillas». «Duermo tranquilo. El recuerdo de los crímenes que cometí se me hace como si no hubiera hecho nada».

«Si uno se pone a pensar sobre esa persona que mató, si se pone a pensar qué va a pasar con sus hijos, qué va a pasar con su familia, yo la maté, la estaban esperando ¿verdad?, si uno se pone a pensar en todo eso, repercute en la mente de uno y se siente uno mal. Por el contrario, si uno no piensa en nada de eso, pues como si nada». «No siento ese sentimiento de culpa sino que simplemente lo alejo de mi mente».

Los pensamientos relacionados con las víctimas y sus familiares «son chispazos nada más, no es algo que me esté atormentando todo el tiempo o por mucho rato, no». «Cuando pienso en las víctimas no siento absolutamente nada, no es algo contra lo que luche sino que viene y se va». En otros momentos «recuerdo a las víctimas y las odio». «Lo que a mí me pasa es que cuando pienso en las víctimas, pienso en el juicio, lo que pasó en el juicio, pienso en todo eso y me viene más coraje». «Pienso que todas eran lacras. Tanto ellas como sus familias son lacras. Será por ese motivo que no me arrepiento». «Yo sabía que eran lacras». Aunque no conociera nada de sus vidas. «Tomé como referencia que ya era muy tarde para que anduvieran afuera, en la calle». «Una mujer tiene que estar temprano en su casa, no tan tarde. Una de ellas decía que era estudiante y no portaba ni un libro, nada. Yo pienso que no era estudiante, que era otra cosa». «Me daba coraje. Quería actuar eliminando lacras». «Al deshacerme de los cuerpos me decía: una lacra menos».

El odio y la destructividad de Mabou se amparan en una ideología persecutoria, en una interpretación irracional que, taponando la posibilidad de sentir culpa, pone a ciertas personas en la diana de un plan de exterminio. Mabou se siente justificado en sus acciones criminales, considerando que las víctimas son merecedoras del trágico final al que él les ha llevado. Sin sentirse apesadumbrado por ello, sino más bien satisfecho, pensando que de esa manera contribuía al bien común. «La misma sociedad me hacía 
ver lo que pasaba. Todo eso me obligaba a ser un justiciero». «No sé si hubieran sido más víctimas o no sé cómo hubiera sido porque el terreno ya no era propicio para enterrar a más gente». «Tendría que deshacerme de los cuerpos de otra manera». «Tal vez metiéndolos dentro de una bolsa y tirándolos lejos de ahí».

«No sé qué opinión tengan mis familiares acerca de los crímenes que cometí, no lo sé, nunca me lo han comentado. Me siguen tratando igual que antes». «Quisiera que me comprendieran». Quisiera que pensaran «que soy un ángel exterminador que elimina lacras, no gente inocente». «Me disgustaría que pensaran que soy un simple asesino que mató por placer, nada más por matar».

\section{a. Narcisismo patológico}

«Hitler, Stalin y Calígula han sido admirados». «En general todos los gobernadores romanos fueron asesinos y han sido admirados». «Yo admiro a los terroristas». «Me gustaría ser visto como una persona que hace una especie de poda, como hacía Stalin. Él eliminaba al que creía que no servía. Como también hacía Hitler. Incluso después de la guerra mucha gente lo considera como un dios. ¿Por qué? Él eliminaba a los que nacían deformes. Si una persona nace deforme, no puede valerse por sí misma. En cierta forma es un parásito, sufre él y sufre su familia. Hitler los eliminaba. Yo estoy de acuerdo con eso». «Desde adolescente me llamó la atención todo lo relacionado con Hitler».

La admiración que siente Mabou por los grandes exterminadores le gustaría también que se la mostraran a él, o más bien, a la "obra" que llevó a cabo y que anhelaba seguir protagonizando, aunque fuera desde el anonimato, en lugar de darse a conocer con motivo de una captura, como así le ocurrió, que interrumpió su "carrera criminal". «Hubiera preferido seguir en el anonimato. Admirarían a un asesino anónimo». «Tal vez me pondrían un apodo como en el caso de Jack el Destripador, que era admirado en su tiempo sin que se supiera quién fue». «Me sentiría satisfecho con el simple hecho de que la gente supiera que hay suelto un asesino en serie». Por un tiempo, cuando las autoridades todavía ignoraban la identidad del asesino serial, Mabou se divertía imaginándose las preguntas que podían plantearse: ¿quién lo hizo?; ¿por qué lo hizo? Después, cuando lo atraparon, se divertía en la Delegación con las investigaciones de los peritos, a quienes consideraba estúpidos e ineptos. 


\section{b. Particularidad del sentimiento de culpa}

Mabou no deja asomar el menor sentimiento de culpa por los crímenes cometidos, cegado emocionalmente como está por una ideología persecutoria por la cual califica a las víctimas y otras personas como parásitos o lacras, seres a incluir en un plan de exterminio. Siente odio por gente desconocida. Además, en ocasiones se complace, en lugar de conmoverse, por las desgracias ajenas. Como Mabou refiere: «He visto que le han pasado cosas a otras personas, como cuando las atropellan y muchos se sienten mal al ver que están heridas. Cuando yo veo así a una persona a veces digo que si le pasó eso es porque hizo algo malo o porque se lo merecía y hasta me siento bien de que sufra. Si está sufriendo es por algo» ${ }^{10}$.

Eso no significa que Mabou esté imposibilitado para sentirse partícipe o responsable ante el sufrimiento que afecta a ciertos seres. «En una ocasión sí sentí algo así, cuando sin querer por tratar de aliviar a un pájaro lo maté. Quería cortarle las uñas. Lo agarré mal y se asfixió y ahí sí me sentí muy mal, incluso hasta lloré». También lamenta no haber sabido ocuparse de otro animal que estaba a su cuidado. «Yo tenía un perro que se murió de una infección y en cierta forma me siento mal porque no lo vacuné; si lo hubiera vacunado, tal vez no se hubiera muerto». Otro momento en el que se activó el sentimiento de culpa fue «cuando mi papá falleció. Se encontraba en el hospital. Estábamos mi mamá y yo con él. Yo le dije a mi mamá que me iba a casa porque me iba a cambiar de ropa y a comer algo y en lo que fui él falleció. Me sentí mal por no haber estado con él cuando falleció. Hasta la fecha siento remordimiento de eso».

Por otra parte, en lo que respecta a la forma de proceder con la tercera víctima, al advertir que se había fugado, «me sentí mal por no haber actuado bien, por no haberla atado bien». «No fui muy precavido, me falló la habilidad y eso me provoca coraje contra mí mismo».

\subsection{Necesidad de sentir}

\footnotetext{
${ }^{10}$ En la escala Atlacholoaya (Amenabar, 2011), construida para la detección de rasgos psicopáticos entre la población reclusa, aparece el siguiente ítem: 10) «El que sufre una desgracia lo tiene merecido. Algo habrá hecho para merecerse eso». Cabe destacar que los ítems (39 en total) se extrajeron a partir de las actitudes y opiniones referidas en entrevistas previas por numerosos presos condenados por delitos violentos.
} 
A partir de las entrevistas que realiza a 5 asesinos en serie, Skrapec (2000, p. 172) refiere que «el acto de matar les hacía sentirse vivos. Sentían un éxtasis eufórico o una ira violenta que al exteriorizar les producía gran placer». Tres de ellos «decían obtener de sus asesinatos una especie de excitación que sobrepasaba todo lo que habían experimentado antes (elevándolos a un nivel superior en el que se veían a sí mismos como omnipotentes), en contraste con una existencia, por lo demás, anodina» (Skrapec, 2000, p. 173). Realmente a ciertos sujetos la utilización de la violencia les resulta excitante e incluso "adictiva", hasta el punto de que desean o necesitan volver a ejercerla tan pronto como tengan oportunidad. Como me decía un recluso entrevistado por mí, «hacer el mal es bonito», «cometer crímenes es estimulante». En México es conocido Arizmendi, un secuestrador que cortaba una de las orejas o ambas a las víctimas y que luego enviaba a sus familiares con objeto de presionarlos en el pago del dinero del rescate. Tras ser capturado, comentó que no secuestraba por dinero sino para poder vivir experiencias emocionantes, que era la actuación delictiva lo que le reportaba gratificación.

\section{a. Anhelando una vivencia extraordinaria}

Antes de la comisión de los crímenes la vida de Mabou «era monótona y aburrida». «Quería algo excitante en mi vida». «Me sentía impulsado a hacer algo diferente, a sentir algo diferente». "A veces fantaseaba con la idea de matar a una persona. Me preguntaba qué se sentiría al matar a alguien; eso me lo he preguntado desde los 17-18 años». «Eso me pareció, aparte de lo más sencillo de hacer, lo más excitante para mí».

Fue en 1997, a los 30 años, cuando Mabou inició su andadura homicida. Esperó más de diez años para matar porque «necesitaba un lugar aislado para hacerlo, hasta que se presentó la oportunidad». «En una ocasión me imaginé quemar los cuerpos en lugar de enterrarlos, pero al quemar un cuerpo se delata por el humo, por el olor, por todo eso. Del lugar donde sucedió mi abuelita platicaba que había sido un panteón y me dije pues qué mejor lugar que un panteón ¿no?». «Cuando se presentó la oportunidad sentía el impulso de hacerlo de forma inmediata, pero anteriormente no sentía apremio».

El primer homicidio no le hizo sentir a Mabou aquello que pretendía o imaginaba sentir. Y ante la decepción que supuso la ausencia de activación emocional, 
volvió a matar. Y volvió a padecer una gran frustración, una sensación de vacío. Por segunda vez. Pero no cesó en su propósito y anhelo. Nuevamente tuvo Mabou la idea de matar, y puso en marcha su plan criminal, a ver si en la tercera ocasión o, si no, en las siguientes lograba acceder al estado experiencial deseado, aunque este homicidio quedó en el intento porque la víctima huyó y luego él fue capturado. En una de las entrevistas me compartió la siguiente reflexión: «A veces pienso si en verdad será una enfermedad mental el asesinar a una persona y no sentir nada».

Mabou tenía la expectativa ilusoria, que llegó a actuar para someterla a prueba, de lograr una activación emocional (significativa) a través de los crímenes, con la idea de que estos constituyeran para él sucesos vivificantes o revitalizadores, y así poder dejar atrás una vida sumamente monótona, anodina, frustrante, que ni siquiera durante las relaciones sexuales le supuso un grado suficiente de placer que le congraciara con su capacidad de sentir. Vivía apenas sin sentir, como muerto en vida. Vacío existencial. Anhedonia (sexual).

\section{b. Noviazgos y relaciones sexuales consensuadas}

A lo largo de su vida Mabou ha mantenido dos relaciones de noviazgo. Cuando tenía 28-29 años, la primera novia «tenía veintidós años. Se me hacía muy inmadura en su forma de ser; por eso no duramos mucho», aproximadamente un año, y sin relaciones sexuales. «En provincia es muy difícil eso; todavía son muy cerrados». Unos dos años después, con la segunda novia, tampoco tuvo Mabou relaciones sexuales. «Con ella duré menos, nada más como seis meses». «No coincidíamos en muchas cosas. A ella le gustaba mucho ir a bailes y a mí no. A mí no me gustaban los lugares donde hay mucha gente o mucho ruido y a ella sí le gustaban».

Las ocasiones en que Mabou tuvo relaciones sexuales consensuadas fue con mujeres que solamente buscaban sexo. La primera vez, aproximadamente a los 28 años, «un amigo me presentó a una señora de esas fáciles que tienen relaciones nada más por gusto, no porque alguien les guste». «En cierta forma no sentí nada, ni placer ni agrado». Tanto en esta primera relación sexual consensuada como en las siguientes, siempre «con el mismo tipo de mujeres», resultaba igual. «Siento excitación, hay erección y todo, y siento satisfacción al practicar el sexo, pero en el momento de 
eyacular no siento nada». Con la eyaculación ${ }^{11}$ deseaba experimentar «pues lo que sienten todos, ¿no?, placer».

Mabou dice haber tenido relaciones sexuales consensuadas con unas ocho mujeres. Eran amigas o conocidas «muy frívolas. Se prestaban al sexo por tener una relación sexual, no por amor». «La forma de pensar de mis novias era muy diferente, pues eran de esas mujeres que cuidan su virginidad hasta que se casan, eran más serias». «Como las quería las respetaba». De todas maneras, mientras andaba con las novias tenía relaciones sexuales con las otras mujeres.

\section{c. Búsqueda perversa de placer}

Mabou tuvo la idea de acceder al orgasmo mediante una relación sexual forzada. Pero no resultó. Durante la violación, al igual que le había ocurrido en las relaciones sexuales consensuadas con diversas mujeres, se sintió decepcionado, frustrado. «Como otras veces, tuve la eyaculación y no sentía nada». Si bien es cierto que Mabou llegó a sentirse excitado durante la violación, su idea de poder sentir el placer sexual máximo imaginado, "un orgasmo fantástico, sensacional", no llegó a producirse. Su problemática sexual remite a las dificultades que en esta área suelen presentar los asesinos seriales, pues, tal como afirma Robert Ressler después de haber analizado una importante casuística, «todos evolucionaron hacia la condición que los psiquiatras califican como adultos sexualmente disfuncionales»(Ressler \& Shachtman, 1995, p. 100).

Además de la búsqueda de placer a través de la violación, Mabou se regocijaba y disfrutaba con la práctica cruel de "jugar" con los sentimientos y las esperanzas de los familiares de las víctimas. Por ejemplo, tres días después de haber matado a su primera víctima (a quien le había preguntado por ciertos datos) Mabou contactó telefónicamente con sus familiares, solicitándoles sesenta mil pesos por ella. «Cuando hablé y colgué el teléfono, no sé por qué, sentía alegría». «Cuando les hablé la segunda vez traté de darles pistas acerca del lugar en que se encontraba la muchacha. Hice un tipo de acertijo y hablé con un hermano suyo. Nada más que por su angustia y miedo no supo

\footnotetext{
${ }^{11}$ Tengamos en cuenta que «si no está acompañada de placer, la eyaculación no disminuye la tensión» (Reich, 2006, p. 718).
} 
entenderlo». Fueron tres llamadas telefónicas en días muy próximos entre sí. «Mi última llamada fue para preguntarles si ya tenían el dinero. Ellos contestaron que sí; entonces yo les dije que les hablaría de nuevo para indicarles en dónde tenían que entregar el dinero, pero ya no les volví a hablar». Estaba "jugando" con los familiares, al mismo tiempo que intentaba despistar a la policía, queriendo hacerles creer que el móvil del secuestro era económico. Con su segunda víctima Mabou no quiso simular el móvil del pago del rescate. «No me atraía esa idea sino que más bien tenía la idea de escribir una carta con un acertijo y enviarla a su familia».

Recordemos que Mabou anhelaba sentir algo diferente, especial, con el propósito de huir de una vida tremendamente monótona, anodina. Sus dificultades para disfrutar del placer (sexual) le llevan a plantearse y probar la destructividad contra los otros. No hay remordimientos ni aspectos compasivos que impidan su búsqueda del placer (unipersonal), a costa del sufrimiento ajeno. Falta de empatía e insensibilidad afectiva combinadas con violencia. A este respecto, y habiendo llegado a este punto del artículo, quisiera destacar como cuestión etiológica que en ciertos sujetos emocionalmente perturbados la incapacidad para sentir (placer sexual) deriva en ansia destructora, lo que viene a avalar la tesis de Wilhelm Reich por la cual «la intensidad de los impulsos destructivos depende del grado de estasis sexual» (Reich, 2006, p. 645), depende del grado de represión que se ejerce contra la sexualidad natural. De hecho, es frecuente encontrar problemas sexuales entre los asesinos seriales. «Casi el $70 \%$ se consideró sexualmente incompetente; el 56\% sufrió disfunción sexual; el 30\% expresó preocupación por el tamaño genital» (Ressler, Burgess \& Douglas, 1995, p. 25). «La razón principal por la que torturan sexualmente y matan es obtener satisfacción sexual y el orgasmo que son incapaces de alcanzar de otra manera» (Knight, 2006, p. 1202).

\section{Discusión y conclusiones}

Ya hemos visto que Mabou se ve impulsado a matar reiteradamente por «la necesidad de sentir algo nuevo y al mismo tiempo para ser un justiciero», dos motivaciones que encontramos en la clasificación aportada por Ronald M. Holmes y colaboradores (1988, 1998), en la que se distinguen cuatro tipos principales de asesinos seriales: 
(i) El asesino visionario. Es un asesino que, padeciendo una severa ruptura con la realidad, mata en respuesta a voces o visiones (alucinatorias) que se lo exigen.

(ii) El asesino misionario. Este tipo de asesino, que no presenta visiones ni voces (alucinatorias), siendo consciente de sus acciones, se arroga la "misión" de librar al mundo de una categoría de personas que considera despreciables.

(iii) El asesino hedonista. Es un asesino que está principalmente orientado hacia el placer o la búsqueda de emociones.

(iv) El asesino dominador/controlador. Este tipo de asesino obtiene intensa satisfacción del proceso de controlar y ejercer el poder sobre la víctima.

«Un asesino serial puede tener múltiples motivos para cometer sus crímenes» (Morton \& Hilts, 2008, p. 17). Por eso, en una de las entrevistas le pedí a Mabou que tratara de ponderar la influencia de las dos motivaciones que me había referido como impulsoras de su actividad criminal, contestándome que «el deseo de sentir algo nuevo era lo que más me impulsaba a matar», en mayor medida que la "obligación" de desempeñarse como justiciero.

Por otra parte, ya hemos visto que Mabou se siente atraído por protagonistas de grandes matanzas, identificándose con ellos, fascinado por diversas vertientes de la criminalidad, pudiendo haberse convertido en terrorista, delincuente neonazi, genocida o asesino en masa si se hubieran dado las circunstancias o posibilidades para concretar y actuar los ensueños y sueños repetitivos de exterminio que nutrían (de forma obsesiva) su deseo.

Antes de su primer homicidio (cometido en 1997, a los 30 años de edad) Mabou no presentó comportamientos antisociales ni nada que aparentemente apuntara su peligrosidad o su inclinación y fascinación por la violencia destructiva. A los ojos de los demás podía dar la impresión de ser totalmente inofensivo, pacífico. No protagonizó actos de rebeldía en el círculo familiar ni en la escuela. Sumamente obediente, mostraba una actitud sumisa, dócil. No se metía en líos. Más bien rehuía, siempre que podía, el contacto social. Solitario empedernido.

¿Cómo es posible entonces que, tras haberse conducido dócil y mansamente durante tantos años, irrumpiera Mabou en la sociedad con una conducta terriblemente destructiva? ¿Acaso se transformó en otro ser de la noche a la mañana? Las respuestas a estas preguntas las hemos de buscar en el proceso de perturbación progresiva que ha 
padecido, en un proceso de conformación psíquica íntimamente relacionado con condiciones históricas tóxicas, pues «no existe una persona que [...] de repente cambie, $\mathrm{y}$, de ser alguien perfectamente normal, pase a transformarse en un ser maligno, destructor, asesino. Las conductas precursoras del asesinato han estado presentes y desarrollándose en la vida de esa persona durante mucho, mucho tiempo... desde la infancia» (Ressler \& Shachtman, 1995, p. 100). El hecho de que algo no haya sido percibido o detectado no significa que no existiera o que no estuviera activo. Quizá las personas que conocían a Mabou no llegaron a advertir sus problemas psicológicos o, si lo hicieron, no le dieron mayor importancia o no pensaron que se tratara de algo tan grave que pudiera afectar trágicamente. La irrupción de Mabou como depredador fue el exponente de una ideación que estaba gestándose de manera larvada, oculta a los ojos de los demás desde mucho tiempo atrás, producto de una personalidad que ha sido gravemente afectada desde la infancia, por condiciones enfermantes, por un aislamiento social sumamente dañino que lo convirtió en un sujeto receloso, desconfiado, que iba albergando y acumulando sentimientos de animadversión y fantasías destructivas.

Mabou odia y ataca a gente desconocida mientras que con las personas que cotidianamente convive, con su propia familia, se expresa continuamente desde la represión de la agresividad, con una actitud conformista y sumisa. Podemos conjeturar que, en este caso, la cantidad ingente de energía agresiva que en las relaciones familiares se ha visto bloqueada, imposibilitada de expresarse, busca una salida, un objeto depositario y es así que, por efecto de la negación y la proyección, se ubica y expresa en los extraños.

Las fantasías criminales las experimenta Mabou con mayor frecuencia a la hora de dormir, cuando la fuerza pulsional impacta notoriamente debido a un relajamiento del sistema defensivo. Estas fantasías son placenteras, como también lo son los sueños repetitivos acerca de una masacre. De todas maneras, las fantasías y los sueños no le resultan suficientes para contener o dar cauce en todo momento a la ira acumulada y quizá por ello, a veces, cuando se encuentra dormido, cuando la energía psíquica asociada al deseo destructivo empieza a desbordarse, generando angustia, es despertado por unos ataques acompañados por "convulsiones", que padece desde niño. En contraste, desde la infancia fue patológicamente reprimida en Mabou su necesidad de descarga agresiva, sin haber podido disponer de un entorno tolerante e implicado en su 
desarrollo emocional, por lo que, aunado con la anhedonia (sexual) y otras variables psicológicas (aislamiento social, susceptibilidad, actitud persecutoria, particularidad del sentimiento de culpa, etc.), esta represión patológica y continuada derivó a partir de la adolescencia en ansia destructora cimentada en un narcisismo patológico (Kernberg, 1987).

A lo largo de su vida a Mabou le faltó la presencia reconfortante, afectuosa y comprensiva de alguien que le ayudara a conectarse con el mundo social, alguien con quien compartir preocupaciones, inquietudes, ilusiones, alguien con quien disfrutar de la ayuda mutua, la ternura, el amor recíproco, alguien con quien poder pensar y visualizar los problemas y las situaciones desde diversas perspectivas y poder elaborar sus traumas, carencias y complejos. Padeció Mabou esa gran falta primordial. Vivió aislado en su propio mundo. Solo con su angustia, susceptibilidad y hostilidad. Deseando la soledad por su temor a ser rechazado o cuestionado en sus capacidades o posibilidades de relación y/o actuación. Convencido de que es mejor estar solo que (mal) acompañado. Pero lo que ocurre es que el aislamiento continuado por decepción o rechazo del mundo externo imposibilita el desarrollo de las potencialidades humanas, las cuales van adquiriendo cuerpo y contenido en las interacciones con los otros. Porque somos seres sociales. Porque nacemos y nos humanizamos en redes sociales. Sirvan al respecto, como reflexión profunda, las siguientes citas:

«Nadie quiere o puede vivir totalmente solo sin arriesgarse a ser un lunático»

(Reich, 1980, p. 101)

«La necesidad de vincularse con otros seres vivos, de relacionarse con ellos, es imperiosa y de su satisfacción depende la salud mental»

(Fromm, 1967, p. 33)

El aislamiento social marginador (Fromm, 1967; Reich, 1980) conlleva la dificultad, cuando no la imposibilidad, de metabolizar los contenidos psíquicos que el sujeto porta consigo, de tal manera que este queda encerrado y atrapado en su mundo interno, a solas con sus deseos, fantasías y sufrimientos que nadie le ayuda a procesar. Hemos de tener en cuenta que, para poder transitar por el desarrollo psicológico 
saludable, el niño precisa de un adecuado sostenimiento (esto es, el acceso a unas figuras confiables y favorecedoras de intercambios con el medio ambiente) (Bion, 1996; Winnicott, 1993) así como de relaciones satisfactorias y placenteras que le hagan sentirse conectado con la vida (Reich, 1985, 2006) y apreciado y respetado como ser humano singular, con opciones y oportunidades para desarrollarse libremente, por lo que el aislamiento social que fuerza al sujeto a la reclusión en su propio mundo apunta en la dirección contraria, conduce a un desarrollo emocional patológico.

Cuando alguien vive a espaldas de la necesaria vinculación con el mundo externo, habiendo padecido graves carencias afectivas y relacionales, frustrado en el amor y la sexualidad, quedará psicológicamente afectado y además en ocasiones a merced de su resentimiento y ánimo de venganza, fuertemente inclinado a hacer vivir a los otros un infierno. Tal como se refiere en diversos trabajos (Fromm, 1967; Knight, 2006; Martens, 2001; Palermo, 2008; Reich, 1980; Ressler \& Shachtman, 1995), el aislamiento social puede impactar negativamente en las emociones, en la capacidad de interacción y en la vida sexual, propiciando la aparición de fantasías y actuaciones destructivas. En este sentido, podemos considerar que las entrevistas en profundidad realizadas con Mabou ofrecen información muy valiosa y reveladora del nexo existente entre su historia de vida y su conformación psíquica $^{12}$, entre los hechos por él protagonizados y sus vivencias, entre sus sueños repetitivos ${ }^{13}$, fantasías y actuaciones violentas y sus deficiencias para vivir el placer y el amor, todo ello fraguado en un aislamiento social continuado y enfermante.

Para concluir, quisiera condensar en una oración la tesis que recorre el presente artículo: cuando un sujeto, especialmente durante su infancia, ha padecido la represión u omisión de sus necesidades vitales (afectivas y psicosexuales) y carece de recursos o ayuda para sanar sus heridas emocionales (Bion, 1996; Miller, 1998; Winnicott, 1993), queda abocado a una vida emocional perturbadora en la cual la destructividad aparece como vía de satisfacción compensatoria y narcisístico-patológica, como respuesta ocultadora de su impotencia para vivir el amor y la sexualidad (Fromm, 1997; Kernberg, 1987; Knight, 2006; Reich, 2006; Skrapec, 2000).

\footnotetext{
${ }^{12}$ La conformación psíquica se va gestando en los vínculos, pues somos quienes somos dependiendo de la historia de interacciones en que hemos participado y participamos.

${ }^{13}$ Los sueños repetitivos expresan inquietudes, ansiedades y/o deseos sumamente significativos.
} 


\section{Agradecimientos}

Quiero dar las gracias a Mabou por su disposición a participar en la investigación, al director de la cárcel en que él se encontraba por las atenciones que tuvo conmigo, a José Luis Musi por las gestiones de investigación carcelaria, a los evaluadores de la REIC por las sugerencias y observaciones que me han permitido mejorar el artículo, y a José Cid (editor de la REIC) por su apoyo y amabilidad.

\section{Financiación}

Este estudio ha sido realizado en el marco de mi proyecto "Readaptación Social de Homicidas", que fue apoyado por el Fondo de Modernización para la Educación Superior (FOMES) en 1999 mientras ejercía como profesor de tiempo completo en la Facultad de Psicología de la Universidad Autónoma del Estado de Morelos, México.

\section{Referencias}

Amenabar, J. M. (2011). La escala Atlacholoaya: Una propuesta para la evaluación de la personalidad antisocial. Revista Española de Investigación Criminológica, 9, art. 7, 1-20.

Amenabar, J. M. (2014). Cómo hacer de un niño un psicópata. Madrid: Biblioteca Nueva.

Bowlby, J. (1982). Los cuidados maternos y la salud mental. Buenos Aires: Humanitas.

Bion, W. R. (1996). Volviendo a pensar. Buenos Aires: Hormé.

Dutton, D. G. \& Golant, S. K. (1997). El golpeador: Un perfil psicológico. Buenos Aires: Paidós.

Fromm, E. (1967). Psicoanálisis de la sociedad contemporánea. México: Fondo de Cultura Económica.

Fromm, E. (1997). Anatomía de la destructividad humana. México: Siglo Veintiuno.

Garrido, V. (2007). La mente criminal. Madrid: Temas de Hoy.

Garrido, V. \& López Lucio, P. (2006). El rastro del asesino. Barcelona: Ariel.

Hare, R. D. (1984). La psicopatía. Barcelona: Herder. 
Hare, R. D. (2000). La naturaleza del psicópata: algunas observaciones para entender la violencia depredadora humana. En A. Raine \& J. Sanmartín (eds.) Violencia y psicopatía (pp. 15-58). Barcelona: Ariel.

Hare, R. D. (2003). Sin conciencia. Barcelona: Paidós.

Holmes, R. M. \& De Burger, J. (1988). Serial murder. Newbury Park, California: Sage.

Holmes, R. M. \& Holmes, S. T. (1998). Serial murder. (2 ed.) Thousand Oaks, California: Sage.

Kerlinger, F. N. \& Lee, H. B. (2002). Investigación del comportamiento. México: McGraw-Hill.

Kernberg, O. F. (1987). Trastornos graves de la personalidad. México: El Manual Moderno.

Knight, Z. G. (2006). Some thoughts on the psychological roots of the behavior of serial killers as narcissists: An object relations perspective. Social Behavior and Personality, 34 (10), 1189-1206.

Martens, W. H. J. (2001). The hidden suffering of the psychopath. Psychiatric Times, $19(1), 1-6$.

Meloy, J. R. (2000). The nature and dynamics of sexual homicide: An integrative review. Aggression and Violent Behavior, 5 (1), 1-22.

Meloy, J. R. (2002). Pathologies of attachment, violence, and criminality. En A. Goldstein (ed.) Comprehensive handbook of psychology, Volume 11: Forensic Psychology (pp. 509-526). New York: John Wiley \& Sons.

Miller, A. (1998). El saber proscrito. Barcelona: Tusquets.

Miller, L. (2014). Serial killers: II. Development, dynamics, and forensics. Aggression and Violent Behavior, 19, 12-22.

Morton, R. J. \& Hilts, M. A. (2008). Serial murder: Multi-disciplinary perspectives for investigators. Quantico: Federal Bureau of Investigation.

Palermo, G. B. (2008). Narcissism, sadism, and loneliness: The case of serial killer Jeffrey Dahmer. En R. N. Kocsis (ed.) Serial murder and the psychology of violent crimes (pp. 85-100). Totowa: Humana Press.

Reich, W. (1980). El asesinato de Cristo. Barcelona: Bruguera.

Reich, W. (1985). La revolución sexual. Barcelona: Planeta-Agostini.

Reich, W. (2006) La función del orgasmo. En Obras Escogidas. Barcelona: RBA. 
Ressler, R. K., Burgess, A. W. \& Douglas, J. E. (1995). Sexual homicide: Patterns and motives. New York: The Free Press.

Ressler, R. K. \& Shachtman, T. (1995). El que lucha con monstruos. Barcelona: Planeta/Seix Barral.

Rojas Marcos, L. (2004). Las semillas de la violencia. Madrid: Espasa.

Skrapec, C. A. (2000). Los motivos del asesino en serie. En A. Raine \& J. Sanmartín (eds.) Violencia y psicopatía (pp. 155-180). Barcelona: Ariel.

Winnicott, D. W. (1993). El niño y el mundo externo. Buenos Aires: Hormé.

Winnicott, D. W. (1996). Deprivación y delincuencia. Buenos Aires: Paidós.

Yakeley, J. \& Meloy, J. R. (2012). Understanding violence: Does psychoanalytic thinking matter? Aggression and Violent Behavior, 17, 229-239.

José Martín Amenabar Beitia es doctor en psicología y miembro asociado de la Escuela Española de Terapia Reichiana. Trabaja como profesor de tiempo completo en la Facultad de Psicología de la Universidad del País Vasco, dedicándose al estudio de los fenómenos psicopatológicos y violentos. 